\title{
Effectiveness of syndromic management for male patients with urethral discharge symptoms in Amazonas, Brazil*
}

\author{
Jonas Rodrigues de Menezes Filho ${ }^{1}$ \\ Enrique Galbán $n^{4,5}$ \\ Carolina Talhari ${ }^{8,9}$
}

\author{
José Carlos Gomes Sardinha' ${ }^{2,3}$ \\ Valéria Saraceni ${ }^{6,7}$
}

DOI: http:/ /dx.doi.org/10.1590/abd1806-4841.20175453

\begin{abstract}
BACKGROUND: Urethral discharge syndrome (UDS) is characterized by the presence of purulent or mucopurulent urethral discharge.The main etiological agents of this syndrome are Neisseria gonorrhoeae and Chlamydia trachomatis.

Овјестіvеs: To evaluate the effectiveness of the syndromic management to resolve symptoms in male urethral discharge syndrome cases in Manaus, Amazonas, Brazil.

METHODS: Retrospective cohort of male cases of urethral discharge syndrome observed at a clinic for sexually transmitted disease (STD) in 2013. Epidemiological and clinical data, as well as the results of urethral swabs, bacterioscopy, hybrid capture for C.trachomatis, wet-mount examination, and culture for N.gonorrhoeae, were obtained through medical chart reviews.

RESULTS: Of the 800 urethral discharge syndrome cases observed at the STD clinic, 785 (98.1\%) presented only urethral discharge syndrome, 633 (79.1\%) returned for follow-up, 579 (91.5\%) were considered clinically cured on the first visit, $41(6.5 \%)$ were considered cured on the second visit, and 13(2.0\%) did not reach clinical cure after two appointments. Regarding the etiological diagnosis, $42.7 \%$ of the patients presented a microbiological diagnosis of N.gonorrhoeae, 39.3\% of non-gonococcal and non-chlamydia urethritis, $10.7 \%$ of C.trachomatis and $7.3 \%$ of co-infection with chlamydia and gonococcus. The odds of being considered cured in the first visit were greater in those who were unmarried, with greater schooling, and with an etiological diagnosis of gonorrhea. The diagnosis of non-gonococcal urethritis reduced the chance of cure in the first visit.

STUDY LIMITATION: A study conducted at a single center of STD treatment.

CONCLUSION: Syndromic management of male urethral discharge syndrome performed in accordance with the Brazilian Ministry of Health STD guidelines was effective in resolving symptoms in the studied population. More studies with microbiological outcomes are needed to ensure the maintenance of the syndromic management.
\end{abstract}

Keywords: Clinical protocols; Sexually transmitted diseases; Therapeutics; Urethral diseases

\section{INTRODUCTION}

Urethral discharge syndrome (UDS) is characterized by the presence of purulent urethral discharge or mucopurulent urethral discharge associated with dysuria, pain when urinating, itching, and foul odor. The main etiological agents of this syndrome are Neisseria gonorrhoeae and Chlamydia trachomatis. ${ }^{1}$ Possible complications of gonococcal urethritis (GU) are locally invasive disease, urethral stenosis, and disseminated gonococcal infection. Non-gonococcal urethritis is usually self-limited, and may cause epididymitis and occasionally conjunctivitis, as well as reactive arthritis. However, with the advent of antibiotics, these complications have become rare. ${ }^{2}$ In 2005, the World Health Organization (WHO) estimated that, in the Americas, the number of cases of men with C. trachomatis infection was 7.98 per million as compared to 1.56 per million cases of N. gonorrhoeae. ${ }^{3}$ In 2008, the same organization estimated that,

\footnotetext{
Received on 01.12.2015.

Approved by the Advisory Board and accepted for publication on 04.08.2016.

* Work performed at Fundação Alfredo da Matta.

Financial support: None.

Conflict of interest: None.

Escola Superior de Saúde (ESA), Urology Course, Universidade do Estado do Amazonas (UEA), Manaus, AM, Brazil.

STD Department, Fundação Alfredo da Matta (FUAM), Manaus, AM, Brazil.

Superintendência de Saúde do Amazonas (SUSAM), Manaus, AM, Brazil.

Epidemiology Department, Instituto Nacional de Gastroentereologia de la Republica de Cuba, Havana, Cuba.

Epidemiology Course, Escola de Medicina de Havana, Havana, Cuba.

Health Surveillance Superintendency, Secretaria Municipal de Saúde do Rio de Janeiro, Rio de Janeiro, RJ, Brazil.

Post-graduate Program in Tropical Medicine, Fundação de Medicina Tropical Dr Heitor Vieira Dourado (FMT-HVD), Manaus, AM, Brazil.

Dermatology Course, Universidade do Estado do Amazonas (UEA), Manaus, AM, Brazil.

Dermatology Department, Fundação Alfredo da Matta (FUAM), Manaus, AM, Brazil.
} 
globally, there would be more than 498.9 million new cases of curable sexually transmitted disease (STD) (syphilis, gonorrhea, chlamydia, and trichomoniasis) in adults of 15-45 years of age. ${ }^{4}$ In Ethiopia, a urethral discharge rate of $13.6 \%$ was found. ${ }^{5}$ In Peru, $15.4 \%$ of men who had sex with men were infected with curable STD, and $5.5 \%$ presented urethral discharge. ${ }^{6}$

In Brazil, according to the Brazilian Ministry of Health, UDS is responsible for approximately $15 \%$ of STD ${ }^{1}$. A study in six Brazilian capital cities identified a prevalence of gonorrhea of $0.9 \%$ and $3.4 \%$ of chlamydia in males. In this study, the Manaus male population presented $3.0 \%$ of chlamydia and $1.3 \%$ of gonorrhea prevalence. ${ }^{7}$ Another study in the northeast region of Brazil verified a $5.2 \%$ prevalence of UDS. ${ }^{8}$ Barbosa et al. (2010), also in Brazil, found a $13.1 \%$ prevalence of Chlamydia trachomatis and an $18.4 \%$ prevalence of Neisseria gonorrhoeae among 767 subjects, of whom $92.9 \%$ were men. ${ }^{9}$

One of the measures adopted to control STD is syndromic management (SM), whose use was established in the early 1990s. ${ }^{10}$ In Brazil, these measures were implemented in $1993,{ }^{11}$ but the algorithms were only recognized in 1998. ${ }^{12}$ This indirect approach to STD is based on the identification of consistent groups of symptoms and easily recognized signs (syndromes), providing treatment that will cover the majority or most serious organisms responsible for the syndrome. ${ }^{1}$ Patients are considered to be cured if the there is a resolution of symptoms. SM also includes other strategies, such as testing for HIV and syphilis, partner notification, STD prevention education and condom provision. ${ }^{1}$

In 1998, an Indonesian study on SM predicted that this approach would have a great impact on the control and prevention of STD and AIDS in both sexes. ${ }^{13}$ Van Dam et al. reported that, in the absence of diagnostic tests for STD etiological agents, SM was effective and appropriate for treating patients with STD. ${ }^{14}$ In Canada, SM has been established as a standard diagnostic and therapeutical approach for patients within high-risk groups, as it was considered cheap, simple, and accurate for the management of STD. ${ }^{15}$ In China and in the USA, SM was considered relatively adequate and effective for the clinical application in UDS. ${ }^{16,17}$ In Italy, SM for urethral discharge had effective treatment results in the first appointment. ${ }^{18}$

The city of Manaus, Amazonas, has a tertiary health service, which is a reference center for the diagnosis and treatment of STD in Brazil, handling an average of 1,000 UDS cases per year.

This study aimed to evaluate the effectiveness of SM of male UDS cases, as proposed by the Brazilian Ministry of Health, using the resolution of symptoms on the first and second follow-up visits after SM as the outcome. In addition, we described the clinical and epidemiological profile of the population studied, as well as the etiological results of UDS.

\section{METHODS}

A retrospective cohort study was conducted at an STD clinic in Manaus, Amazonas, Brazil, during 2013. This clinic covers a population of more than 2,000,000 people. Although this health care facility has the equipment and trained personnel required for the etiological diagnosis of STD, the clinic also uses the syndromic approach to quickly diagnose and treat those infections, but saving bacteriological diagnosis for those who do not respond to SM.
Medical records of male patients with UDS who visited the STD clinic at Fundação Alfredo da Matta (FUAM STD) from January 2013 to December 2013 were reviewed by the investigators. Both sociodemographic and clinical data were extracted using a data extraction form designed for the study.

The presence of mucopurulent or purulent urethral discharge was confirmed by checking the retracted foreskin or after compressing the base of the penis towards the glans, as described elsewhere. ${ }^{19}$ Patients were then prescribed first-line drugs recommended by the Brazilian Ministry of Health STD guidelines. ${ }^{1}$

The outcome was defined as a clinical cure or "cure after $\mathrm{SM}^{\prime \prime}$ if there were no signs nor symptoms of UDS after treatment in the first follow-up visit, nor after the use of second-line drugs in the second follow-up visit of the patient.

The cohort characteristics analyzed in this study were age, schooling, marital status, race, STD past history, number of steady sex partners upon diagnosis and in the preceding three months, engagement in casual sex, as well as sexual orientation, frequency of condom use, and type of access to the STD clinic. Clinical data of the patients included in the study, such as the duration of symptoms in days, previous treatment for STD, SM drugs prescribed, return for the next appointment or not, and clinical cure after the first and second consultations, were compiled from medical records.

All patients underwent laboratory tests to identify the etiological agent. SM, in accordance with the Brazilian Ministry of Health guidelines, was started for all patients, without awaiting the laboratory results. No lab work was done to confirm bacteriological cure. Two urethral swabs were used, one for bacterioscopy and hybrid capture (HC2 digene kit CT-ID DNA test, Qiagen ${ }^{\circledR}$, Gaithersburg, Maryland-USA) to detect C. trachomatis and another for culture and wet-mount examination to detect $N$. gonorrheae. ${ }^{1,17}$ Peripheral blood was collected to conduct serological tests for HIV, hepatitis B and C, treponemic rapid test, and Venereal Disease Research Laboratory (VDRL) for syphilis.

Data were analyzed using the statistical package STATA 11.0 (Stata Corp LP, College Stattion, TX 77845, USA). Pearson's Chi-squared test was used to analyze differences between categorical variables. The Student's t-test or the Wilcoxon test were used to compare continuous variables, whenever applicable, at a $5 \%$ significance level. Univariate and multivariate analyses were performed using logistic regression, looking for a possible association of independent variables with the clinical cure outcome. Variables with a p-value of $<0.20$ in the univariate analysis were included in the multivariate model, and those that reached a p-value of $<0.05$ in the multivariate analysis remained in the univariate model.

The Fundação Alfredo da Matta Institutional Review Board approved this study, logged under protocol number 760.037 on August, 21, 2014. No patient identifiers were used, and the pooled data analysis preserved the subjects' privacy.

\section{RESULTS}

Of the 800 UDS cases observed at the STD clinic in 2013, 785 (98.1\%) presented only USD, while 15 presented UDS in association with a genital ulcer syndrome. Six-hundred and thirty-three subjects (79.1\%) returned for follow-up visits; of these, 579 (91.5\%) 
were considered clinically cured in the first visit and 41 (6.5\%) in the second visit. Therefore, 620 (98\%) were considered cured after SM, and $13(2.0 \%)$ remained symptomatic after SM (Figure 1$)$.

The mean age was 23 years (range: 19-30 years). The majority of cases $(65.7 \%)$ had completed eight years of schooling, $87.5 \%$ were brown-skinned and $73.3 \%$ were unmarried. Five-hundred and ten patients $(92.1 \%)$ reported being heterosexual and $340(58.2 \%)$ claimed to have sexual activity with more than one steady partner upon diagnosis, $135(21.3 \%)$ denied engaging in any casual sex, while 185 (29.2\%) reported one, 109 (17.2\%) two, and 204 (32.2\%) 3 or more casual sex partners. Most patients included in the study (59.4\%) claimed to occasionally use a condom. Of the 800 patients included in the study, 301 (70.9\%) received medical care at the FUAM STD clinic spontaneously, without formal referral from other health facilities. Most patients (76.5\%) reported no previous treatment for STD. One-hundred and one cases (16\%) complained of UDS-related symptoms for 2 days prior to seeking care, 213 (33.7\%) for three to five days, $157(24.8 \%)$ for 6 to 10 days, while 162 patients $(25.5 \%)$ presented clinical symptoms for more than 10 days. Regarding the etiological diagnosis, $42.7 \%$ of the patients had a confirmed diagnosis of Neisseria gonorrhoeae, $39.3 \%$ of non-gonococcal urethritis and non-chlamydia infection, $10.7 \%$ of Chlamydia trachomatis, and $7.3 \%$ of dual infection with both chlamydia and gonococcus. Among the evaluated patients, $19(5.6 \%, \mathrm{p}=0.052)$ presented a concomitant diagnosis of syphilis (VDRL and rapid test were positive), 14 (2.3\%, $\mathrm{p}=0.052)$ tested positive for HIV, and $2(0.8 \%, \mathrm{p}=0.477)$ presented a positive serology for hepatitis B (Table 1).

Comparing those patients who returned after SM with those missed their follow-up appointment, it was possible to observe that there was a lower proportion of consistent condom use among those who missed their appointment $(\mathrm{p}=0.048)$, as well a higher proportion of gonococcal infection among these patients $(\mathrm{p}<0.001)$ (Table 1$)$.

The characteristics of patients who were considered clinically cured on the first follow-up visit were compared with those who had their symptoms resolved only after the second-line treat-

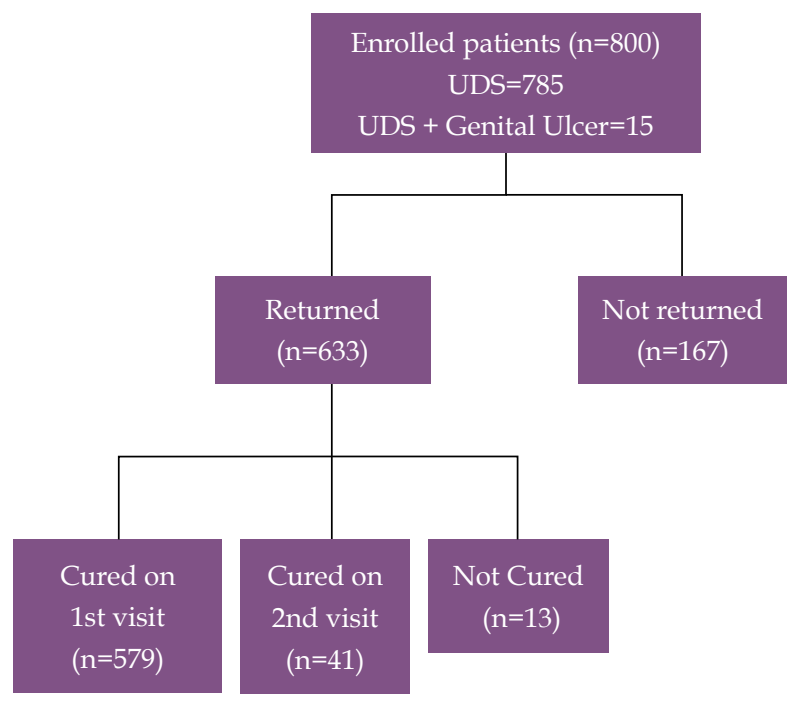

FIGURE 1: Flowchart of cases with urethral discharge syndrome (UDS) enrolled at FUAM in 2013 ment. In the univariate analysis using logistic regression, factors significantly associated with cure on the first visit were age [OR $=0.97$ (95\%CI 0.94-0.99)], being unmarried [OR=2.20 (95\%CI 1.14-4.23)], etiological diagnosis of gonorrhea [OR=2.18 (95\%CI 1.10-4.43)], etiological diagnosis of non-gonococcal urethritis [OR $=0.45(95 \% \mathrm{CI}$ 0.24-0.85)], and more than 8 years of schooling [OR=1.91 (95\% CI 0.99-3.67)], which had a borderline significance (Table 2).

In this study, two models of multivariate analysis were constructed. In table 3, it can be observed that the odds of clinical cure for gonorrhea cases in the first visit after SM were 2.3 times higher $[\mathrm{OR}=2.30(95 \% \mathrm{CI}$ 1.08-4.86)] when compared to other etiological diagnoses, after controlling for age and education. However, when the patient had non-gonococcal urethritis, the odds of cure in the first visit were reduced by $51 \%$ [OR=0.49 (95\%CI 0.25-0.96)], also controlling for age and education (Table 4).

\section{DISCUSSION}

This study aimed to investigate the effectiveness of SM in male patients with UDS who received medical care at an STD clinic in the city of Manaus. The average age of the studied population is consistent with other epidemiological studies of STD worldwide and in Brazil, whose reported average age ranged from 15 to 49 years of age. The unmarried marital status, prevalent in this study, is also the most reported by other authors. ${ }^{4,20}$ Approximately one third of men with UDS included in the study reported having more than three casual sex partners. A study carried out in Kisumu, Kenya, reported that $61.2 \%$ of men with UDS were single and $53 \%$ had more than four sex partners. ${ }^{21}$

Regarding education, in this study $65.7 \%$ reported having more than 8 years of schooling. A study conducted in the northeast of Brazil showed that only $12.9 \%$ of patients with UDS had studied for over 8 years. ${ }^{9}$ Despite the apparent higher education reported in this study, condom use was reported as occasional in most cases (59.4\%) and, among those who did not return after the first visit, the scenario was even worse $(67.1 \%)$. This suggests that this population either had limited access to condoms and/or that sexual education or the already established health policies in place are not reaching this group, leading to an increase in the incidence of STD and their complications. ${ }^{1.22}$

In this study, most cases $(70.9 \%)$ sought care directly at the FUAM STD clinic without referral, despite the fact that this clinic is considered of tertiary complexity, but delivers easy access to trained staff in the reception area, to STD specialists, to immediate treatment, as well as to laboratory tests.

Among the 633 patients who returned, 579 (91.5\%) were considered cured in the first visit and $41(6.5 \%)$ in the second visit, with 620 (98\%) of clinical cure, pointing to the fact that SM was effective, as was also reported by Vuylsteke, with a cure rate of $99 \%$. In Senegal, SM was effective in $84.6 \%$ of cases. ${ }^{17,23}$ A study conducted in Andhra Pradesh (India) compared SM and laboratorial data for diagnosis and concluded that the simple combination of laboratory tests and syndromic management can increase its effectiveness. ${ }^{24}$

Regarding the etiological diagnosis, $42.7 \%$ of the cases presented an etiological diagnosis of Neisseria gonorrhoeae, 39.3\% presented cases of non-gonococcal and non-chlamydia urethritis, $10.7 \%$ 
TABLE 1: Proportional distribution of sociodemographic characteristics of male urethral discharge syndrome cases by returning to follow-up appointment after syndromic management, FUAM STD clinic, 2013

\begin{tabular}{|c|c|c|c|}
\hline Characteristics & Return $=$ Yes $n=633(79.1 \%)$ & Return $=$ No $n=176(20.9 \%)$ & p-value \\
\hline Average age & $23(19-30)$ & $24(20-30)$ & 0.525 \\
\hline \multicolumn{4}{|l|}{ Education } \\
\hline Up to 8 years & $200(34.3)$ & $52(32.3)$ & 0.820 \\
\hline$>8$ years & $383(65.7)$ & $104(66.7)$ & \\
\hline \multicolumn{4}{|l|}{ Skin color } \\
\hline Brown & $499(87.5)$ & $137(89.5)$ & 0.500 \\
\hline Others & $71(12.5)$ & $16(10.5)$ & \\
\hline \multicolumn{4}{|l|}{ Marital status } \\
\hline Single & $431(73.3)$ & $124(79.0)$ & 0.147 \\
\hline Others & $157(26.7)$ & $33(21.0)$ & \\
\hline \multicolumn{4}{|l|}{ Sexual orientation } \\
\hline Heterosexual & $510(92.1)$ & $143(95.3)$ & 0.170 \\
\hline Homosexual / Bi/MSM & $44(7.9)$ & $7(4.7)$ & \\
\hline \multicolumn{4}{|l|}{ Current steady sex partner } \\
\hline$>1$ & $340(58.2)$ & $92(58.0)$ & 0.954 \\
\hline None & $244(41.8)$ & $66(42.0)$ & \\
\hline \multicolumn{4}{|l|}{ Casual sex partner } \\
\hline 0 & $135(21.3)$ & $40(24.0)$ & 0.880 \\
\hline 1 & $185(29.2)$ & $45(27.0)$ & \\
\hline 2 & 109 (17.2) & $28(16.8)$ & \\
\hline$>3$ & $204(32.2)$ & $54(32.2)$ & \\
\hline \multicolumn{4}{|l|}{ Condom use } \\
\hline Always & $80(14.8)$ & $11(7.4)$ & 0.048 \\
\hline Sometimes & $320(59.4)$ & $100(67.1)$ & \\
\hline Never & $139(25.8)$ & $38(25.5)$ & \\
\hline \multicolumn{4}{|l|}{ Type of access } \\
\hline Spontaneously seeking care & $301(70.9)$ & $82(72.6)$ & 0.728 \\
\hline Referral & $126(29.1)$ & $31(27.4)$ & \\
\hline \multicolumn{4}{|l|}{ Previous STD treatment } \\
\hline No & $484(76.5)$ & $131(78.4)$ & 0.589 \\
\hline Yes & $149(23.5)$ & $36(21.6)$ & \\
\hline \multicolumn{4}{|l|}{ Duration of symptoms (days) } \\
\hline$>2$ & $101(16.0)$ & $23(13.8)$ & 0.142 \\
\hline 3 to 5 & $213(33.7)$ & $69(41.3)$ & \\
\hline 6 to 10 & $157(24.8)$ & $44(26.4)$ & \\
\hline$>10$ & $162(25.5)$ & $31(18.5)$ & \\
\hline \multicolumn{4}{|l|}{ Clinical cure } \\
\hline On 1st visit & $579(91.5)$ & & - \\
\hline On 2nd visit & $41(6.5)$ & & \\
\hline Not cured & $13(2.0)$ & & \\
\hline Lost to follow-up & - & $167(100.0)$ & \\
\hline \multicolumn{4}{|l|}{ Etiological Diagnosis } \\
\hline Gonorrhea & $268(42.7)$ & $92(55.4)$ & $<0.001$ \\
\hline Chlamydia & $67(10.7)$ & $3(1.8)$ & \\
\hline Both & $46(7.3)$ & $2(1.2)$ & \\
\hline NGNCU & $246(39.3)$ & 69 (41.6) & \\
\hline \multicolumn{4}{|l|}{ Positive serology result } \\
\hline VDRL + TRT & $19(5.6)$ & $1(1.0)$ & 0.052 \\
\hline $\mathrm{HBV}$ & $2(0.8)$ & $0(0.0)$ & 0.477 \\
\hline $\mathrm{HCV}$ & $0(0.0)$ & $0(0.0)$ & - \\
\hline HIV & $14(2.3)$ & $0(0.0)$ & 0.052 \\
\hline
\end{tabular}

MSM: men who make sex with men; NGNCU: non-gonococcal and non-chlamydia urethritis; TRT: treponemic rapid test

Source: FUAM UDS Database, 2013. Note: The sum of cases for each variable changed according to the number of missing data. 
TABLE 2: Univariate analysis of the characteristics of urethral discharge syndrome cases for cure in the first visit versus cure in the second post-treatment visit through syndromic management, FUAM, 2013

\begin{tabular}{|c|c|c|c|}
\hline Characteristics & OR & $95 \% \mathrm{CI}$ & p-value \\
\hline Age (years) & 0.97 & 0.94-0.99 & 0.13 \\
\hline Education $>8$ years & 1.91 & $0.99-3.67$ & 0.052 \\
\hline Brown skin color & 0.37 & $0.09-1.55$ & 0.172 \\
\hline Marital status: single & 2.20 & $1.14-4.23$ & 0.019 \\
\hline Sexual orientation: heterosexual & 1.00 & $0.29-3.39$ & 0.998 \\
\hline Current steady sex partner: 1 or + & 0.54 & $0.26-1.10$ & 0.088 \\
\hline \multicolumn{4}{|l|}{ \# Casual sex partner last 3 months } \\
\hline 0 & 1.00 & - & - \\
\hline 1 & 0.93 & $0.42-2.07$ & 0.859 \\
\hline 2 & 3.07 & $0.83-11.29$ & 0.092 \\
\hline 3 or more & 1.56 & $0.66-3.70$ & 0.316 \\
\hline \multicolumn{4}{|l|}{ Condom use } \\
\hline Always & 1.00 & - & - \\
\hline Sometimes & 1.35 & $0.52-3.52$ & 0.538 \\
\hline Never & 0.85 & $0.31-2.36$ & 0.306 \\
\hline Spontaneously seeking care & 1.04 & $0.48-2.26$ & 0.914 \\
\hline STD previous treatment (Yes) & 1.08 & $0.50-2.32$ & 0.842 \\
\hline \multicolumn{4}{|l|}{ Duration of symptoms (days) } \\
\hline Up to 2 & 1.00 & - & - \\
\hline 3 to 5 & 0.25 & $0.56-1.11$ & 0.068 \\
\hline 6 to 10 & 0.27 & $0.58-1.24$ & 0.091 \\
\hline$>10$ & 0.25 & $0.05-1.14$ & 0.073 \\
\hline \multicolumn{4}{|l|}{ Etiological diagnosis } \\
\hline Gonorrhea & 2.18 & $1.10-4.43$ & 0.032 \\
\hline Chlamydia & 0.69 & $0.28-1.70$ & 0.416 \\
\hline Both & - & - & - \\
\hline NGNCU & 0.45 & $0.24-0.85$ & 0.014 \\
\hline
\end{tabular}

NGNCU: non-gonococcal and non-chlamydia urethritis Source: FUAM UDS Database, 2013.

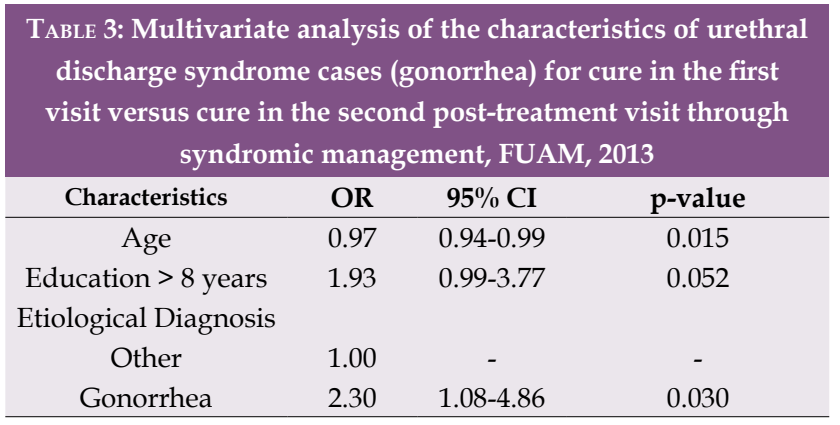

Source: FUAM UDS Database, 2013.

presented Chlamydia trachomatis, while $7.3 \%$ of the patients were coinfected with chlamydia and gonococcus. These data corroborate the WHO estimates of the incidence and prevalence of STD worldwide. ${ }^{4}$

Gonococcal resistance to antimicrobials are increasingly being reported. ${ }^{25-29}$ Despite this fact, we were able to show that SM was effective in a male UDS cohort that was managed as outlined in the Brazilian Ministry of Health STD guidelines, in an STD clinic in Manaus, Amazonas.

The loss of 167 patients due to missed follow-up appointments represented a limitation to this study. However, the two groups - those who returned and those who were lost due to missed

\begin{tabular}{|c|c|c|c|}
\hline Characteristics & OR & $95 \%$ CI & p-value \\
\hline Age & 0.97 & 0.94-0.99 & 0.025 \\
\hline Education $>8$ years & 1.86 & $0.95-3.62$ & 0.068 \\
\hline \multicolumn{4}{|l|}{ Etiological Diagnosis } \\
\hline Other & 1.00 & - & - \\
\hline NGNCU & 0.49 & $0.25-0.96$ & 0.037 \\
\hline
\end{tabular}

NGNCU: non-gonococcal andnon-chlamydia urethritis Source: FUAM UDS Database, 2013.

follow-up appointments - presented very similar characteristics. Thus, it could be inferred that the non-return could be associated with non-clinical healing, since the clinical cure was very high among those who returned $-91.5 \%$ of the cases were cured on the first visit, that is, upon receiving first-line treatment. Resolution of symptoms among all who returned - after the first or second visit was even greater (98\%). Most patients who did not return had a lab diagnosis of gonorrhea, which was associated with a cure rate that was 2.3 times higher than those with other etiological diagnosis. Therefore, it can be inferred that non-return equals symptoms' resolution, leading to a sense of well-being and no need for further care. 
Another limitation of this study was the inability to identify the etiological agent in cases of non-gonococcal and non-chlamydia UDS. Nevertheless, even in those cases, SM was effective.

\section{CONCLUSION}

Therefore, the impact of SM, avoiding progression to STD complications, breaking the chain of transmission and providing sexual education and counseling to patients, reinforces its effec-

\section{REFERENCES}

1. Brasil. Ministério da Saúde. Secretaria de Vigilância em Saúde. Programa Nacional de DST e Aids. Manual de Controle das Doenças Sexualmente Transmissíveis. Brasilia: Ministério da Saúde; 2005. 140p. Série Manuais n.o 68.

2. Centers for Disease Control and Prevention (CDC). Update to CDC's sexually transmitted diseases treatment guidelines, 2010: oral cephalosporins no longer a recommended treatment for gonococcal infections. MMWR Morb Mortal Wkly Rep. 2012;61:590-4.

3. World Health Organization, Department of Reproductive Health and Research Prevalence and incidence of selected sexually transmitted infections. Methods and Results, used by WHO to generate 2005 estimates. Geneva: World Health Organization; 2011.

4. World Health Organization, Department of Reproductive Health and Research. Global incidence and prevalence of selected curable sexually transmitted infections - 2008. Geneva: World Health Organization; 2012.

5. Moges B, Yismaw G, Kassu A, Megabiaw B, Alemu S, Amare B, et al. Sexually transmitted infections based on the syndromic approach in Gondar town, northwest Ethiopia: a retrospective study. BMC Public Health. 2013;13:143.

6. Perez-Brumer AG, Konda KA, Salvatierra HJ, Segura ER, Hall ER, Montano SM, et al. Prevalence of HIV, STIs, and Risk Behaviors in a Cross- Sectional Communityand Clinic-Based Sample of Men Who Have Sex with Men (MSM) in Lima, Peru. PLoS One. 2013;8:e59072.

7. Brasil. Ministério da Saúde. Secretaria de Vigilância em Saúde. Programa Nacional de DST e Aids. Prevalências e frequêencias relativas de Doenças Sexualmente Transmissiveis (DST) em populações selecionadas de seis capitais brasileiras, 2005. Brasília: Ministério da Saúde; 2008. 224 p. (Série G. Estatística e Informação em Saúde).

8. Cavalcante EG, Araújo MA, Galvão MT, de Moura HJ, Gondim AP, da Silva RM, et al. Sexually transmitted infections associated syndromes assisted in the primary health care in Northeast, Brazil. BMC Public Health. 2012;12:595.

9. Barbosa MJ, Moherdaui F, Pinto VM, Ribeiro D, Cleuton M, Miranda AE. Prevalence of Neisseria gonorrhoeae and Chlamydia trachomatis infection in men attending STD clinics in Brazil. Rev Soc Bras Med Trop. 2010:43:500-3.

10. WHOStudy Group on Management of Sexually Transmitted Diseases Patiensts. WHO Technical Report Series, 810: Management of Patients with Sexually Transmitted Diseases: reporto f a WHO group. Geneva: World Health Organisation; 1990.

11. Vuylsteke B, Ramos M, D'Angelo LA, Fernandes M, Laga M, Dallabetta G. Quality of STD case management in primary health care centers in Brazil. International Congress of Sexually Transmitted Diseases, Seville, Spain, 19-22 October 1997. (Abstract 103).

12. Moherdaui F, Vuylsteke B, Siqueira LF, dos Santos Júnior MQ, Jardim ML, et al Validation of national algorithms for the diagnosis of sexually transmitted diseases in Brazil: results from a multicenter study. Sex Transm Infect. 1998;74:S38-43.

13. Djajakusumah T, Sudigdoadi S, Keersmaekers K, Meheus A. Evaluation of syndromic patient management algorithm for urethral discharge. Sex Transm Infect. 1998;74:S29-33.

14. Van Dam CJ, Becker KM, Ndowa F, Islam MQ. Syndromic approach to STD case management: where do we go from here? Sex Transm Infect. 1998;74:S175-8.

15. Redwood-Campbell L, Plumb J. The syndromic approach to treatment of sexually transmitted diseases in low-income countries: issues, challenges, and future directions. J Obstet Gynaecol Can. 2002;24:417-24. tiveness to male UDS. However, further studies in this setting, as well as and others to monitor possible SM therapeutic failures due to bacterial resistance, are warranted. Moreover, whenever feasible, prospective studies with microbiological cure assessment should be conducted to reinforce the safe use of SM.

This study showed that SM, as part of STD management, can be safely applied to male UDS, in accordance with the current Brazilian STD guidelines. $\square$
16. Wang Q, Yang P, Zhong M, Wang G. Validation of diagnostic algorithms for syndromic management of sexually transmitted diseases. Chin Med $\mathrm{J}$ (Engl). 2003;116:181-6.

17. Pettifor A, Walsh J, Wilkins V, Raghunathan P. How effective is syndromic management of STI? Sex Transm Dis. 2000;27:371-85

18. Di Carlo A. Sexually transmitted diseases syndromic approach: urethral discharge. G Ital Dermatol Venereol. 2012;147:389-94.

19. Brasil. Ministério da Saúde. Secretaria de Políticas de Saúde Programa Nacional de DST e Aids. Técnicas para coleta de secreções. Brasilia Ministério daSaúde; 2001.

20. Da Ros CT, Schmitt Cda S. Global epidemiology of sexually transmitted disease. Asian J Androl. 2008:10:110-4.

21. Otieno FO, Ndivo R, Oswago S, Ondiek J, Pals S, McLellan-Lemal E, et al. Evaluation of syndromic management of sexually transmitted infections within the Kisumu Incidence Cohort Study. Int J STD AIDS. 2014;25:851-9.

22. Shrivastava SR, Shrivastava PS, Ramasamy J. Utility of syndromic approach in management of sexually transmitted infections: public health perspective. Journal of Coastal Life Medicine. 2014;2:7-13

23. Vuylsteke B. Current status of syndromic management of sexually transmitted infections in developing countries. Sex Transm Infect. 2004;80:333-4.

24. Prabha ML, Sasikala G, Bala S. Comparison of syndromic diagnosis of reproductive tract infections with laboratory diagnosis among rural married women in Medak district, Andhra Pradesh. Indian J Sex Transm Dis. 2012;33:112-5.

25. Belland RJ, Morrison SG, Ison C, Huang WM. Neisseria gonorrhoeae acquires mutations in analogous re- gions of gyrA and parC in fluoroquinolone-resistant isolates. Mol Microbiol. 1994;14:371-80.

26. Unemo M, Shafer WM. Antibiotic resistance in Neisseria gonorrhoeae: origin, evolution, and lessons learned for the future. Ann N Y Acad Sci. 2011:1230:E19-28.

27. Lombardi C, Siqueira LFG, Santos Junior MFQ, Francisco W, Belda W. Neisseria gonorrhoeae produtora de penicilinase. Primeira cepa isolada em São Paulo, SP (Brasil). Rev Saúde Públ. 1985;19:374-6.

28. Starnino S; GASP-LAC Working Group, Galarza P, Carvallo ME, Benzaken AS, Ballesteros AM, et al. Retrospective analysis of antimicrobial trends (20002009) in Neisseria gonorrhoeae isolates from countries in Latin America and the Carribean shows evolving resistance to ciprofloxacin, azithromycin and decreased susceptibility to ceftriaxone. Sex Transm Dis. 2012;39:813-21.

29. Kirkcaldy RD, Zaidi A, Hook EW 3rd, Holmes KK, Soge 0, del Rio C, et al. Neisseria gonorrhoeae antimicrobial resistance among men who have sex with men and men who have sex exclusively with women: the Gonococcal Isolate Surveillance Project, 2005-2010. Ann Intern Med. 2013;158:321-8.

MAILING ADDRESS:
Jonas Rodrigues de Menezes Filho
Av. Carvalho Leal, 1777
Bairro Cachoeirinha
69065-130 Manaus, AM
Brazil
E-mail: jonas_filho2003@yahoo.com.br

How to cite this article: Menezes Filho JR, Sardinha JCG, Galban E, Saraceni V, Talhari C. Effectiveness of syndromic management for male patients with urethral discharge symptoms in Amazonas, Brazil. An Bras Dermatol. 2017;92(6): 779-84. 